\title{
Temporal visual resolution and disease severity in MS
}

Noah Ayadi, Jan Dörr, MD, Seyedamirhosein Motamedi, MSc, Kay Gawlik, MSc, Judith Bellmann-Strobl, MD, Janine Mikolajczak, PhD, Alexander U. Brandt, MD, Hanna Zimmermann, PhD, * and Friedemann Paul, MD*

Neurol Neuroimmunol Neuroinflamm 2018;5:e492. doi:10.1212/NXI.0000000000000492

\section{Abstract}

\section{Objective}

To examine temporal visual resolution assessed as critical flicker frequency (CFF) in patients with MS and to investigate associations with visual system damage and general disability and cognitive function.

\section{Methods}

Thirty-nine patients with MS and 31 healthy controls (HCs) were enrolled in this crosssectional study and underwent CFF testing, high- and low-contrast visual acuity, alertness and information processing speed using the paced auditory serial addition task (PASAT), and retinal optical coherence tomography (OCT). In patients with MS, visual evoked potentials (VEPs) and Expanded Disability Status Scale (EDSS) scores were assessed.

\section{Results}

CFF in patients with MS (mean \pm SD: $40.9 \pm 4.4 \mathrm{~Hz}$ ) was lower than in HCs $(44.8 \pm 4.4 \mathrm{~Hz}, p<$ 0.001). There was no significant CFF difference between eyes with and without previous optic neuritis $(\mathrm{ON})$. CFF was not associated with visual acuity, VEP latency, the peripapillary retinal nerve fiber layer thickness, and the combined ganglion cell and inner plexiform layer volume. Instead, reduced CFF was associated with worse EDSS scores $\left(\mathrm{r}^{2}=0.26, p<0.001\right)$ and alertness $\left(\mathrm{r}^{2}=0.42, p=0.00042\right)$ but not with PASAT $(p=0.33)$.

\section{Conclusion}

CFF reduction in MS occurs independently of $\mathrm{ON}$ and structural visual system damage. Its association with the EDSS score and alertness suggests that CFF reflects global disease processes and higher cortical processing rather than focal optic nerve or retinal damage.

\author{
Correspondence \\ Dr. Dörr \\ jan-markus.doerr@charite.de
}

*Equally contributing senior authors.

From the Charité-Universitätsmedizin Berlin (N.A., J.D., S.M., K.G., J.B.-S., J.M., A.U.B., H.Z., F.P.), Corporate Member of Freie Universität Berlin, Humboldt-Universität zu Berlin, and Berlin Institute of Health, NeuroCure Clinical Research Center; Neurology Department (J.D.), Multiple Sclerosis Center, Oberhavel Clinic, Henningsdorf; Experimental and Clinical Research Center (J.B.-S., F.P.), Max Delbrueck Center for Molecular Medicine and Charité-Universitätsmedizin Berlin, Corporate Member of Freie Universität Berlin, HumboldtUniversität zu Berlin, and Berlin Institute of Health; and Department of Neurology (F.P.), Charité-Universitätsmedizin Berlin, Corporate Member of Freie Universität Berlin, HumboldtUniversität zu Berlin, and Berlin Institute of Health, Germany.

Funding information and disclosures are provided at the end of the article. Full disclosure form information provided by the authors is available with the full text of this article at Neurology.org/NN.

The Article Processing Charge was funded by Neurology: Neuroimmunology \& Neuroinflammation.

This is an open access article distributed under the terms of the Creative Commons Attribution-NonCommercial-NoDerivatives License 4.0 (CC BY-NC-ND), which permits downloading and sharing the work provided it is properly cited. The work cannot be changed in any way or used commercially without permission from the journal. 


\section{Glossary}

ART = automatic real-time; $\mathbf{C F F}=$ critical flicker frequency; EDSS = Expanded Disability Status Scale; GCIP = ganglion cell and inner plexiform layer; GEE = Generalized estimating equation; $\mathrm{HC}=$ healthy control; HCVA = high-contrast visual acuity; ICC = intraclass correlation coefficient; $\mathbf{I N L}=$ inner nuclear layer; $\mathbf{L C L A}=$ Low-contrast letter acuity; $\mathbf{O C T}=$ optical coherence tomography; $\mathbf{O N}$ = optic neuritis; PASAT = paced auditory serial addition task; $\mathbf{p R N F L ~ = ~ P e r i p a p i l l a r y ~ r e t i n a l ~ n e r v e ~ f i b e r ~ l a y e r ~}$ thickness; RRMS = relapsing-remitting MS; RT = reaction time; $\mathbf{S E}=$ standard error; TAP = Test of Attentional Performance; TMV = total macular volume; VEP = visual evoked potential.

Afferent visual pathway damage in MS results from acute focal damage, i.e., by optic neuritis $(\mathrm{ON})$ or chronic diffuse damage, ${ }^{1-3}$ which leads to visual dysfunction and has a relevant impact on the quality of life of patients. ${ }^{4}$ Thus, clinical assessment of the visual pathway by means of high-contrast visual acuity (HCVA), functional assessment by means of visual evoked potentials (VEP), ${ }^{5}$ and more recently also structural assessment by optical coherence tomography (OCT) have become integral in diagnosing and monitoring patients with MS. ${ }^{6}$

An intriguing aspect of visual function is the visual temporal resolution, commonly assessed as the critical flicker frequency (CFF). ${ }^{7}$ CFF represents the frequency of a pulsed light source, from which an individual perceives the signal as flickering. Braunstein already reported in 1903 that CFF was decreased in optic atrophy and other ophthalmologic conditions. ${ }^{7,8}$ From the 1950 s onward, CFF was investigated in MS, ${ }^{9}$ and decreased CFF was found to relate to $\mathrm{ON},{ }^{9-11}$ but independence from $\mathrm{ON}$ was also reported. ${ }^{12,13}$ Furthermore, higher cortical processes had an impact on CFF in patients with cerebral injuries ${ }^{14}$ and hepatic encephalopathy. ${ }^{15}$

Despite these early studies suggesting CFF as a potentially important marker for visual function, it remains unclear how CFF could serve as a marker for monitoring disease severity in MS. Our study is thus aimed at evaluating the potential of CFF measurements by investigating its association with clinical and cognitive assessments and structural visual system damage assessed by OCT.

\section{Methods}

\section{Patients and controls}

Forty-two patients with relapsing-remitting MS (RRMS) and 31 healthy controls (HCs) were enrolled in this prospective, cross-sectional pilot study. Inclusion criteria were diagnosis of RRMS according to the 2010 revised McDonald criteria ${ }^{16}$ (or $\mathrm{HC}$ ) and age between 18 and 70 years. Exclusion criteria were any comorbidity (e.g., glaucoma, retinal disease, diabetes mellitus, ophthalmologic surgery), which could influence vision or the retina. Patients with MS were recruited consecutively over 5 years (2012-2017) from the NeuroCure Clinical Research Center, Berlin. HCs were recruited from volunteers.

To match the groups for sex and age, the 3 oldest female patients with MS were excluded before analysis, leading to a final number of 39 patients included in the analysis.

All patients with MS underwent clinical assessment and were scored using the Expanded Disability Status Scale (EDSS) ${ }^{17}$ A demographic and clinical overview is given in table 1.

\section{Standard protocol approvals, registrations, and patient consents}

This study was conducted in line with the strengthening the reporting of observational studies in epidemiology statement ${ }^{18}$ and was approved by the local ethics committee (EA1/216/11). It was conducted in accordance with the Declaration of Helsinki in its applicable version and applicable German laws. All participants provided written informed consent.

Table 1 Cohort description

\begin{tabular}{llll}
\hline & MS & HC & p Value \\
\hline Participants, N & 39 & 31 \\
\hline Sex, male/female (N) & $13 / 26$ & $12 / 19$ & $0.6\left(\chi^{2}\right)$ \\
\hline Age/years, mean \pm SD (range) & $45.9 \pm 8.4(27-66)$ & $45.0 \pm 16.1(20-70)$ \\
\hline Eyes with previous ON, yes/no (N) & $28 / 50$ & $0.6(\mathrm{MWU})$ \\
\hline Time since diagnosis, mo, mean \pm SD (range) & $156.8 \pm 92.3(24-446)$ & \\
\hline EDSS, median (range) & $2.5(0-6)$ & \\
\hline
\end{tabular}

Abbreviations: EDSS = Expanded Disability Status Scale; HC = healthy control; MWU = Mann-Whitney U test; ON = optic neuritis. 


\section{Critical flicker frequency}

CFF measurement was performed monocularly using a HEPAtonorm analyzer (nevoLAB GmbH, Maierhöfen, Germany) in a quiet and semidarkened room. The device includes a headset that shields any external light from the participant's eyes and that features intrafoveal visual stimulation with a red luminous diode. The initial light signal of 60 $\mathrm{Hz}$ is perceived as continuous by the participant. Participants were instructed to press a stop button as soon as they perceive a flickering signal. When the operator starts the measurement on a hand-held controller, the pulse frequency decreases until it is perceived as flickering. The corresponding pulse frequency is defined as CFF and recorded by the hand-held controlling unit. CFF thresholds were determined monocularly, where each eye was tested 8 times, and the mean CFF (mCFF) value was calculated. All participants underwent a training session with 5 measurements before each initial measurement session. ${ }^{15,19}$

\section{Visual function parameters}

HCVA was assessed with the Functional Vision Analyzer Optec 6500P system (Stereo Optical Co, Chicago, IL), as described previously. ${ }^{20}$ Testing was performed monocularly under habitual correction and photopic conditions $(85 \mathrm{~cd} /$ $\mathrm{m}^{2}$ ) with Early Treatment of Diabetic Retinopathy Study charts in a simulated distance of $20 \mathrm{ft}^{20}$ Low-contrast letter acuity (LCLA) was assessed binoculary with $2.5 \%$ contrast Sloan charts in $2 \mathrm{~m}$ distance. $^{21}$

Visual evoked potentials (VEP) were tested using the Dantec Keypoint VEP system (Natus Europe GmbH, Planegg, Germany). The P100 latency was measured using a standard black-and-white checkerboard stimulation $\left(15^{\prime} / 50-60^{\prime}\right.$, at 1 $\mathrm{m}$ ) and were recorded from the $\mathrm{Oz}$ electrode against a $\mathrm{Cz}$ reference electrode according to the 10-20 International System. The P100 amplitude was not analyzed.

\section{Alertness and cognitive parameters}

Because of time constraints, denial by participants and technical issues, only a subset of 17 patients with MS and $20 \mathrm{HCs}$ underwent a selected task from the computerized test of attentional performance (TAP) battery for alertness testing. ${ }^{22}$ The tasks consist of a simple visual reaction time (RT) task without an acoustic warning signal, called tonic alertness task (part A) and a visual RT task preceded by an acoustic warning signal, phasic alertness (part B). To measure alertness, several trials were undertaken by alternating part $\mathrm{A}$ and part $\mathrm{B}$. The participant was then asked to respond as fast as possible by pushing a button whenever a cross is displayed. ${ }^{22}$ Mean RTs from tests without acoustic warning signal were considered a measure of alertness.

Also because of time constrains, only a subset of 29 patients with MS were tested with the 3-second version of the paced auditory serial addition task (PASAT), a measure of information processing speed. ${ }^{23}$ For 14 patients, both alertness and PASAT testing were available.

\section{OCT and intraretinal segmentation}

All participants underwent retinal examination using a spectral domain OCT (Spectralis SD-OCT; Heidelberg Engineering, Heidelberg, Germany) using Eye Explorer 1.9.10.0 and automatic real-time (ART) image averaging. ${ }^{24}$ Peripapillary retinal nerve fiber layer thickness ( $\mathrm{pRNFL}$ ) was derived from a standard ring scan around the optic nerve head $\left(12^{\circ}, 1536 \mathrm{~A}\right.$-scans, $\left.16 \leq \mathrm{ART} \leq 100\right)$ using segmentation by the device's software with viewing module 6.0.14.0. A macular volume scan $\left(25^{\circ} \times 30^{\circ}, 61 \mathrm{~B}\right.$-scans, $768 \mathrm{~A}$-scans per B-scan, $12 \leq \mathrm{ART} \leq 15)$ was acquired for total macular volume (TMV) including all retinal layers from the inner limiting membrane and Bruch membrane, as determined by the device's segmentation software within a 6-mm diameter cylinder around the fovea.

Intraretinal segmentation of combined ganglion cell and inner plexiform layer (GCIP) volume and inner nuclear layer (INL) volume was performed on macular scans with the Johns Hopkins OCT layer segmentation method (AURA Tools

Figure 1 Critical flicker frequency measurements in healthy controls

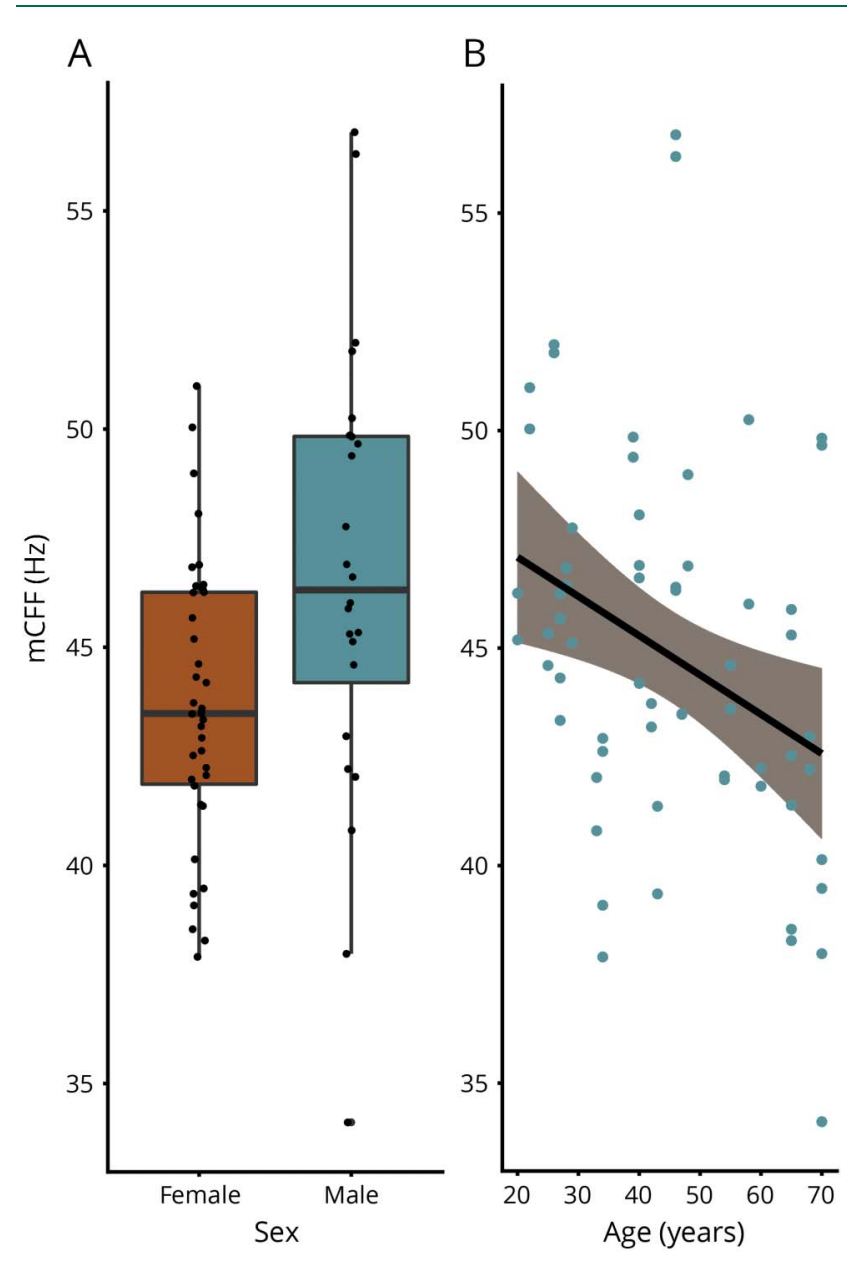

Comparison of CFF measurements between female and male HCs (A) and association of CFF measurements with age (B). $\mathrm{HC}=$ healthy control; $\mathrm{mCFF}=$ mean critical flicker frequency. 
version 1.2$)^{25}$ combined with in-house pre-processing (cropping of volume scans to $6 \times 6 \mathrm{~mm}$ ) and postprocessing tools (graphical user interface for manual correction of segmentation results). All OCT scans were carefully checked for retinal changes unrelated to MS, sufficient quality, ${ }^{26,27}$ segmentation errors, and were manually corrected by a blinded experienced grader if necessary.

\section{Statistical analysis}

Statistical analyses were performed with $\mathrm{R}$ version 3.1.2 including geepack package 1.2-0. For demographic comparisons between patients and HCs, the Pearson $\chi^{2}$ test for sex and nonparametric Mann-Whitney $U$ test for age were used. Generalized estimating equation (GEE) models with working correlation matrix "exchangeable" and corrected for age and sex were used for group comparisons and associations involving eye-related measurements to account for withinsubject intereye effects. GEE results are given with regression coefficient (B) and standard error (SE). All measurements were treated as continuous variables, and groups were stratified within patients with $\mathrm{MS}$ in $\mathrm{ON}$ and non-ON eyes. For the assessment of the test-retest reliability, the intraclass correlation coefficient (ICC) and its 95\% confidence intervals were estimated using the R ICC package. ${ }^{28}$ As suggested in a previous study, we considered an ICC greater than 0.9 as high and as moderate if between 0.8 and $0.9 .^{29}$ Statistical significance was established at $p<0.05$. A correction for multiple comparisons with the Bonferroni-Holm method was performed for all correlation analyses. ${ }^{30}$

\section{Data availability}

All data of this study will be shared by request from any qualified investigator.

\section{Results}

\section{CFF in $\mathrm{HC}$}

$\mathrm{HC}$ had an $\mathrm{mCFF}$ of $44.8 \pm 4.4 \mathrm{~Hz}$. There was no mCFF difference between female and male HCs (43.70 \pm 3.24 vs 46.6 $\pm 5.3 \mathrm{~Hz}, \mathrm{~B}=1.7188, \mathrm{SE}=4.06, p=0.67$ ) (figure $1 \mathrm{~A}$ ), but lower $\mathrm{mCFF}$ was associated with higher age $(\mathrm{B}=-0.090, \mathrm{SE}=0.043$, $p=0.036$ ) (figure $1 \mathrm{~B}$ ) in $\mathrm{HC}$. Also, in $\mathrm{HC}$, there was no association between $\mathrm{mCFF}$ and HCVA $(\mathrm{B}=2.30, \mathrm{SE}=1.99, p=$ $0.34), \mathrm{mCFF}$ and LCLA $(\mathrm{B}=0.029, \mathrm{SE}=0.078, p=0.71)$, or VEP P100 latency $(B=0.044, S E=0.042, p=0.29)$. Likewise, alertness did not correlate with $\mathrm{mCFF}(\mathrm{B}=-0.011, \mathrm{SE}=$ $0.0093, p=0.25)$. Mean results are presented in a supplemental file (table e-1, links.lww.com/NXI/A65). The test-retest reliability in HC was high, with an ICC value of 0.91 (0.87-0.94).

\section{CFF in MS}

$\mathrm{mCFF}$ in patients with MS was lower than in $\mathrm{HC}(40.9 \pm 4.72$ $\mathrm{Hz}, \mathrm{p}<0.001)$. There was no difference between $\mathrm{ON}$ and non-ON eyes $(39.7 \pm 5.22$ vs $41.5 \pm 4.33 \mathrm{~Hz}, p=0.094)$ (figure 2). $\mathrm{mCFF}$ was also not associated with visual function as determined by HCVA, LCLA, VEP latencies, and retinal OCT parameters pRNFL (global and papillomacular bundle),
Figure 2 Critical flicker frequency measurements

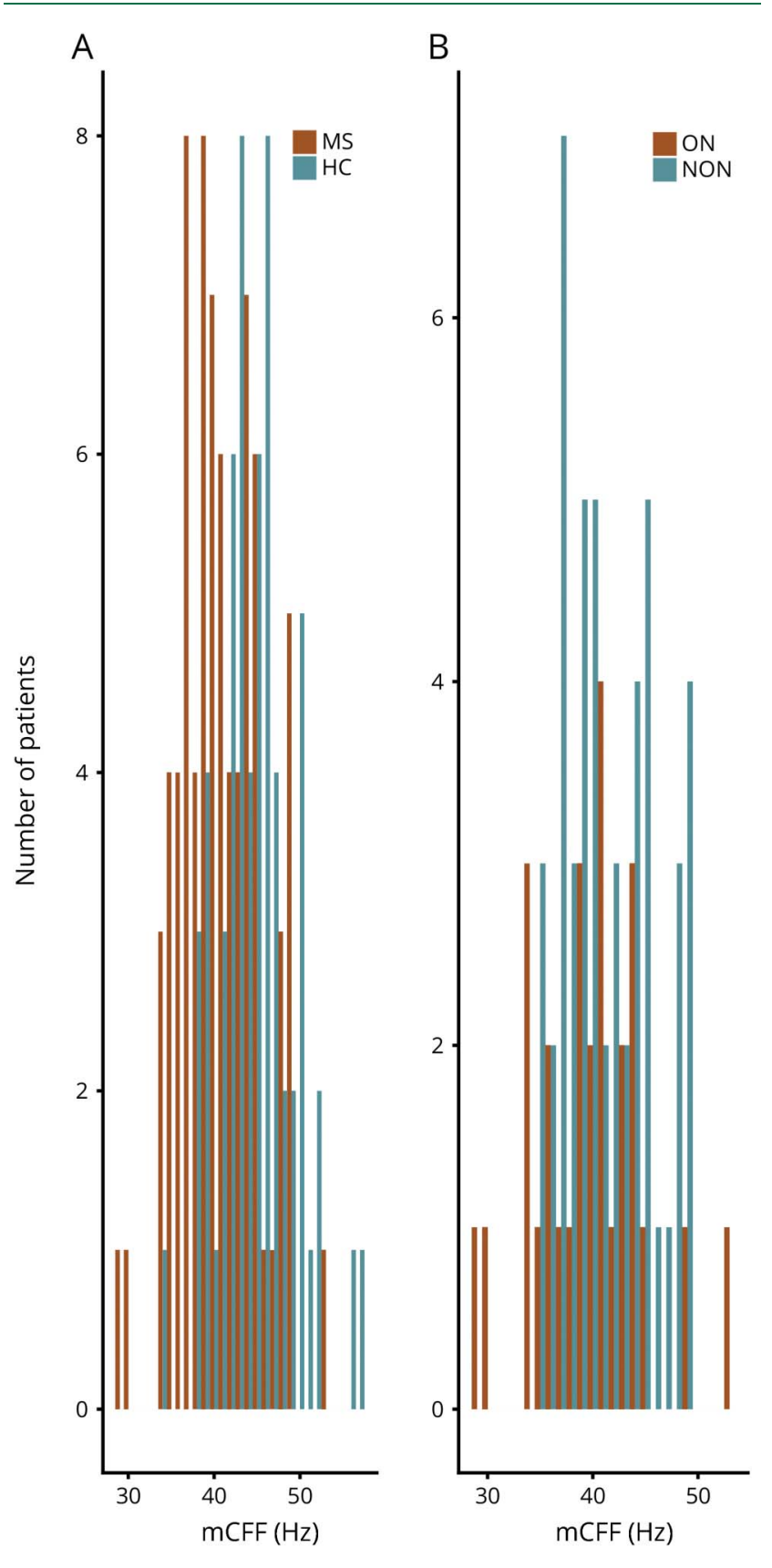

Comparison of CFF measurements between HCs and patients with MS (A) and comparison of CFF measurements between eyes with optic neuritis (ON) and eyes without ON (NON) in patients with MS (B). $\mathrm{HC}=$ healthy control; mCFF = mean critical flicker frequency.

GCIP, INL, and TMV (figure 3). Mean results are presented in a supplemental file (table e-1, links.lww.com/NXI/A65). The test-retest reliability was moderate, with an ICC value of 0.89 (0.85-0.92).

\section{CFF and disability}

We then investigated whether CFF was associated with overall disability, alertness, and information processing speed in MS patients. Here, overall disability was found as higher EDSS scores, which was inversely correlated with lower 
Figure 3 Critical flicker frequency measurements and visual function in MS
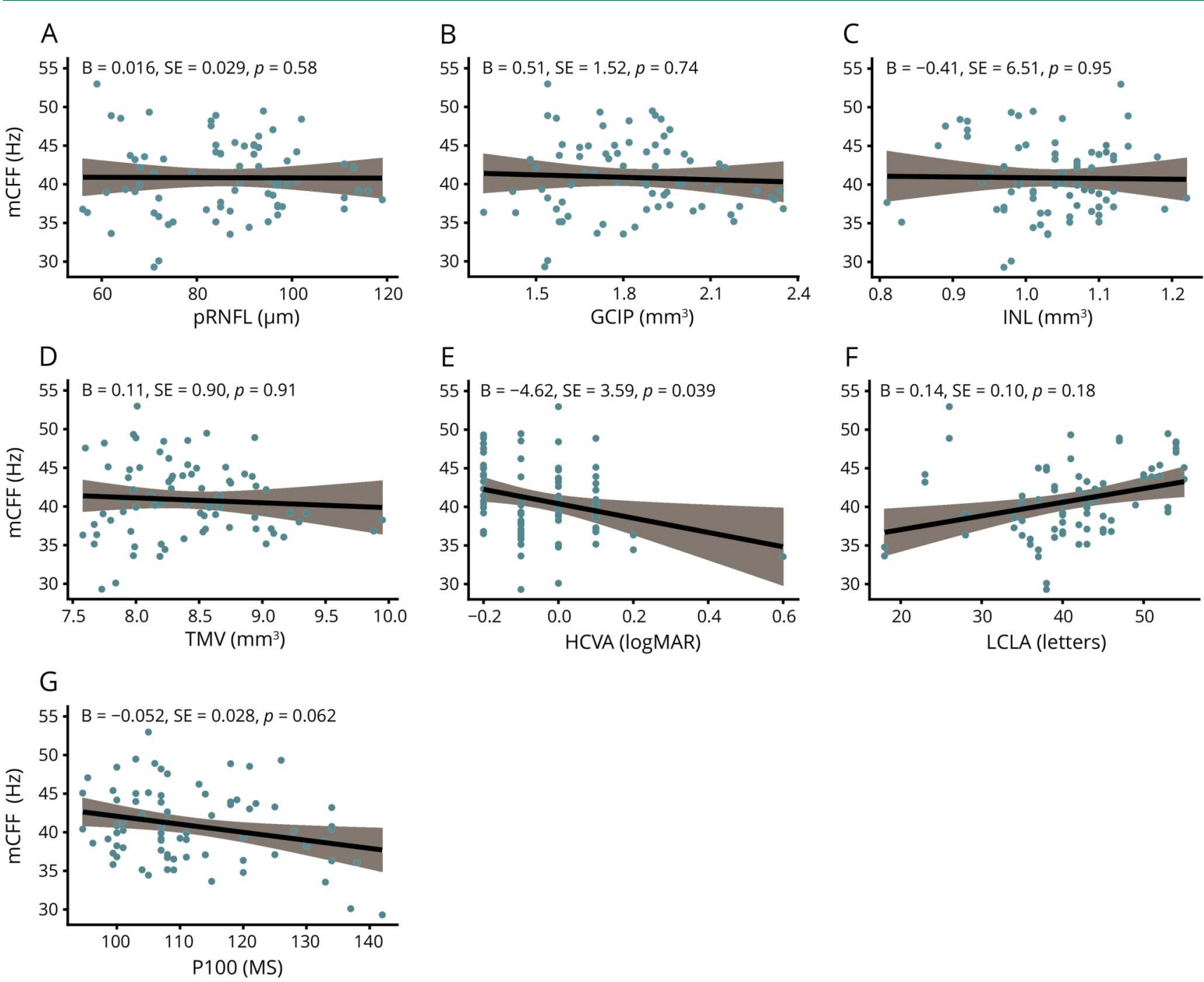

Association of CFF measurements with structural and visual functional parameters: pRNFL (A), GCIP (B), INL (C), TMV (D), HCVA (E), LCLA (F), P100 (G). After BonferroniHolm correction, no $p$ value remained significant. GCIP = ganglion cell/inner plexiform layer; $\mathrm{HCVA}=$ high-contrast visual acuity; $I N L=$ inner nuclear layer; $L C L A=$ lowcontrast letter acuity; $\mathrm{mCFF}$ = mean critical flicker frequency; $\mathrm{PRNFL}$ = peripheral retinal nerve fiber layer; $\mathrm{TMV}$ = total macular volume; VEP = visual evoked potential.

$\operatorname{mCFF}\left(\mathrm{r}^{2}=0.26, \mathrm{~B}=-1.77, \mathrm{SE}=0.50, p=0.00036\right)$ (figure 4A). Moreover, lower $\mathrm{mCFF}$ was associated with worse alertness $\left(\mathrm{r}^{2}=0.42, \mathrm{~B}=-0.048, \mathrm{SE}=0.014, p=0.00042\right)$ (figure $4 \mathrm{~B}$ ), but not with information processing speed, assessed by PASAT ( $\mathrm{B}=0.063, \mathrm{SE}=0.065, p=0.33$ ). After Bonferroni-Holm correction, the associations between $\mathrm{mCFF}$ and alertness and between $\mathrm{mCFF}$ and EDSS remained significant. The SD of the CFF measurements was not associated with alertness $(\mathrm{B}=0.0015, \mathrm{SE}=0.0035, p=0.68)$.

\section{Discussion}

In this study, we investigated the visual temporal resolution by means of CFF assessment in patients with MS. Key findings are as follows: (1) CFF is reduced in MS compared with $\mathrm{HC}$; (2) CFF is not or only weakly associated with structural and functional measures of afferent visual system damage in MS; and (3) by contrast, CFF is associated with alertness and clinical disability.

Previous studies consistently reported impaired CFF in MS and ON., ${ }^{9,12}$ Some investigators interpreted these results as support for cortical damage causing impairment at the central perceptual-discriminative level. ${ }^{9,31}$ Thus, they recommended $\mathrm{CFF}$ as a general measure of cortical processing capacity. ${ }^{32} \mathrm{On}$ the other hand, neuroaxonal degeneration in the retina and the visual pathway of patients with MS could affect CFF as well. ${ }^{9}$

Perception of high-frequency stimuli has been suggested to be influenced by retinal ganglion cells. ${ }^{32}$ Furthermore, cells of the magnocellular system are confirmed to be more sensitive to higher temporal frequency stimulation than cells of the parvocellular system. ${ }^{33}$ Thus, we postulated that CFF could 
Figure 4 Critical flicker frequency measurements in patients with MS
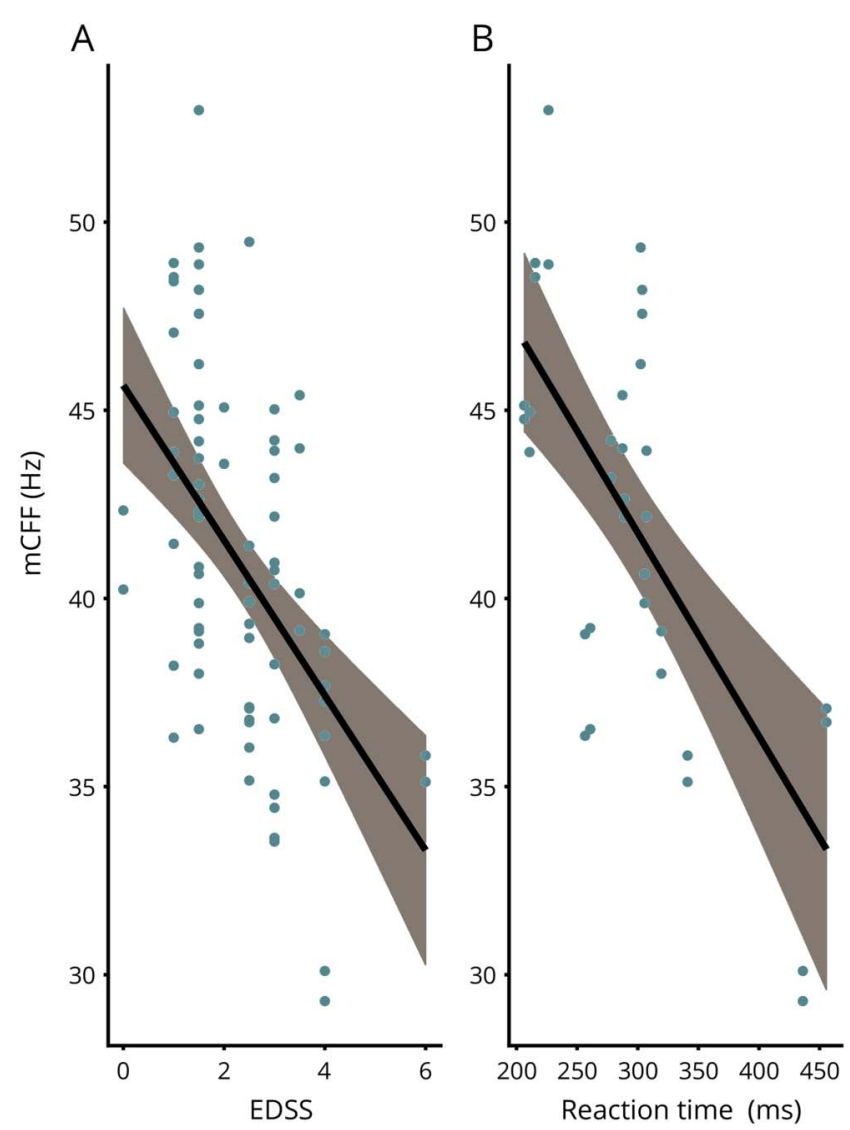

Association of CFF measurements with the EDSS $(A)$ and with reaction time in MS (B). EDSS = Expanded Disability Status Scale; $\mathrm{mCFF}=$ mean critical flicker frequency.

reflect integrity of the magnocellular retinal cells' ability to detect higher frequency stimuli, ${ }^{34}$ and damage of magnocellular retinal ganglion cells might specifically cause decreased CFF. However, our results show no significant association of CFF with any afferent visual system marker, indicating that retinal neuroaxonal retinal damage had no or only negligible influence to CFF in patients with MS. ${ }^{34,35}$ These findings could be explained by effects being small and masked by other associations. However, neuroaxonal retinal damage and demyelination of our MS cohort seem to be comparable to other MS cohorts regarding OCT and VEP measurements. ${ }^{36,37}$

By contrast, our results showed that lower CFF values are associated with longer RTs in a test of alertness, whereas there is no association with CFF SD. This suggests that the association of CFF with alertness is not caused by impaired alertness reducing the ability to comply with the CFF assessment. Tonic alertness refers to a cognitive control of wakefulness and arousal in the absence of a warning and is part of the domain of attention. ${ }^{38}$ It is based on the activation of frontoparietal and partly thalamic regions of the right hemisphere. $^{38}$ Alertness was shown to be impaired after appearance of right hemispheric lesions, ${ }^{38}$ and we could report an association with MS-related fatigue in an earlier study. ${ }^{39}$ This suggests that impaired CFF reflects damage to higher cognitive areas involved in alertness and cognition. Contrarily, the PASAT, which focuses on information processing speed, the cognitive domain most commonly affected in MS, showed no association with CFF in our study.

CFF also correlated with overall disability as represented by the EDSS score. Studies from the 1950/1960s already suggested an association of CFF with general disease disability, but did not investigate this systematically. ${ }^{9,40}$

CFF measurements from our $\mathrm{HC}$ are in line with previous studies regarding the mean CFF and an increase of CFF with age. ${ }^{41}$ However, although 1 study found sex differences in CFF, this difference was not significant in our study. ${ }^{42}$ The ICC values for CFF measurements in HC and MS showed that this method produces reliable results.

Our study has several limitations. Sample sizes of $<40$ in both MS and control groups might have been insufficient to detect small effects. This is particularly important for a potential effect of a previous ON on the CFF, which was not significant in our study, but gave a low $p$ value indicative of a potential power issue. Moreover, the subsets with available TAP and PASAT tests were even smaller, and differences in sample size due to some technical problems and time restrictions in the assessment of the measurements may have resulted in a selection bias potentially weakening our conclusions. We therefore might have missed an association of CFF to information processing as assessed by PASAT. It should also be noted that exclusion of the 3 oldest patients has to be regarded critically because higher age is associated with decreased CFF and impaired visual parameters potentially influencing our findings in regard of the absence of associations between CFF and visual parameters. All visual parameters were measured monocularly except the LCLA because of unavailability at the beginning of the study, potentially reducing the validity of its comparison to monocularly measured CFF values. We did not perform MRI in our study, so we have no information on the association of radiologic disease activity and CFF. Likewise, we have only cross-sectional measurements, so the dynamics of CFF in context of the disease course and any causal inferences remain unclear. It is important to note that most previous studies on CFF in ON and MS were published in the 1950-1970s. ${ }^{1-13}$ Thus, test procedures regarding CFF and other parameters might differ, making comparison of our results to these previous ones difficult. The interpretation of the findings of this study is mostly based on the absence of association with functional and visual parameters. Therefore, we believe that adding MRI and conducting longitudinal observations would be the next step in validating CFF measurements in MS.

Our study showed that visual temporal resolution as assessed by CFF is impaired in patients with MS independent of visual and structural visual system damage. Whether CFF 
can serve as a marker for overall disease activity warrants further investigation.

\section{Author contributions}

N. Ayadi: assessed CFF data, performed statistical analysis, and drafted the manuscript. J. Dörr: conceived the study and critically revised the manuscript. S. Motamedi and K. Gawlik: analyzed OCT data and critically revised the manuscript. J. Bellmann-Strobl, J. Mikolajczak, and A.U. Brandt: contributed to data interpretation and critically revised the manuscript. H. Zimmermann: contributed to the design of the study and data interpretation and drafted the manuscript. F. Paul: contributed to the design of the study and data interpretation and critically revised the manuscript.

\section{Acknowledgment}

The authors thank Cynthia Kraut and Katharina Stößlein for excellent technical support. They also thank Claudia Chien for English proofreading.

\section{Study funding}

This study was supported by a research grant by Novartis Pharma GmbH (Germany). F. Paul is supported by Deutsche Forschungsgemeinschaft (DFG Exc 257).

\section{Disclosure}

N. Ayadi reports no disclosures. J. Dörr served on the advisory boards of Bayer, Novartis, Sanofi Genzyme, and Merck Serono; received travel funding from Novartis, Sanofi Genzyme, Biogen, and Bayer and speaker honoraria from Novartis, Merck Serono, Sanofi Genzyme, Biogen, and Roche; and received research support from Novartis and Bayer. S. Motamedi has a patent pending for method for estimating shape parameters of the fovea by optical coherence tomography. K. Gawlik has a patent pending for retinal image analysis. J. Bellmann-Strobl received travel funding and speaker honoraria from Bayer, Sanofi-Aventis/Genzyme, Merck, and Teva. J. Mikolajczak received travel funding and/or speaker honoraria from Teva, Biogen, Bayer, and Novartis. A.U. Brandt has a patent pending for perceptive visual computing based motor function analysis, MS biomarker, and retinal image analysis; serves on the executive board of IMSVISUAL; received research support from Novartis, Biogen, BMWi, BMBF, University of California, Irvine, and The Guthy Jackson Charitable Foundation; and holds stock or stock options held in Motognosis and Nocturne. H. Zimmermann received speaker honoraria from Teva and Bayer and received research support from Novartis. F. Paul served on the scientific advisory boards of Novartis and MedImmune; received travel funding and/or speaker honoraria from Bayer, Novartis, Biogen, Teva, Sanofi-Aventis/ Genzyme, Merck Serono, Alexion, Chugai, MedImmune, and Shire; is an academic editor of PLoS One and an associate editor of Neurology: Neuroimmunology \& Neuroinflammation; consulted for Sanofi Genzyme, Biogen, MedImmune, Shire, and Alexion; and received research support from Bayer, Novartis, Biogen, Teva, Sanofi-Aventis/Genzyme, Alexion,
Merck Serono, German Research Council, Werth Stiftung of the City of Cologne, German Ministry of Education and Research, Arthur Arnstein Stiftung Berlin, Arthur Arnstein Foundation Berlin, Guthy Jackson Charitable Foundation, and NMMS. Full disclosure form information provided by the authors is available with the full text of this article at Neurology.org/NN.

Received March 14, 2018. Accepted in final form June 25, 2018.

\section{References}

1. Martínez-Lapiscina EH, Sanchez-Dalmau B, Fraga-Pumar E, et al. The visual pathway as a model to understand brain damage in multiple sclerosis. Mult Scler 2014;20: $1678-1685$.

2. Kuchling J, Brandt AU, Paul F, Scheel M. Diffusion tensor imaging for multilevel assessment of the visual pathway: possibilities for personalized outcome prediction in autoimmune disorders of the central nervous system. EPMA J 2017;8:279-294.

3. Backner Y, Kuchling J, Massarwa S, et al. Anatomical wiring and functional networking changes in the visual system following optic neuritis. JAMA Neurol 2018;75: 287-295.

4. Schinzel J, Zimmermann H, Paul F, et al. Relations of low contrast visual acuity, quality of life and multiple sclerosis functional composite: a cross-sectional analysis. BMC Neurol 2014;14:31.

5. Halliday AM, McDonald WI, Mushin J. Visual evoked response in diagnosis of multiple sclerosis. Br Med J 1973;4:661-664.

6. Brandt AU, Martinez-Lapiscina EH, Nolan R, Saidha S. Monitoring the course of MS with optical coherence tomography. Curr Treat Options Neurol 2017;19:15.

7. Brenton RS, Thompson HS, Maxner C. Critical flicker frequency: a new look at an old test [internet]. In: New Methods of Sensory Visual Testing. New York: Springer; 1989:29-52. Available at: link.springer.com/chapter/10.1007/978-1-4613-8835-7_3.

8. Braunstein EP. Beitrag zur Lehre des intermittierenden Lichtreizes der gesunden und kranken Retina. Z Psychol Physiol Sinnesorgan 1903;33:171-206, 241-288.

9. Parsons OA, Miller PN. Flicker fusion thresholds in multiple sclerosis. AMA Arch Neurol Psychiatry 1957;77:134-139.

10. Titcombe AF, Willison RG. Flicker fusion in multiple sclerosis. J Neurol Neurosurg Psychiatry 1961;24:260-265.

11. Galvin RJ, Regan D, Heron JR. Impaired temporal resolution of vision after acute retrobulbar neuritis. Brain 1976;99:255-268.

12. Daley ML, Swank RL, Ellison CM. Flicker fusion thresholds in multiple sclerosis: a functional measure of neurological damage. Arch Neurol 1979;36:292-295.

13. Patterson VH, Foster DH, Heron J, Mason RJ. Multiple sclerosis: luminance threshold and measurements of temporal characteristics of vision. Arch Neurol 1981;38:687-689.

14. Bender MB, Teuber HL. Disturbances in visual perception following cerebral lesions. J Psychol 1949;28:223-233.

15. Sharma P, Sharma BC, Puri V, Sarin SK. Critical flicker frequency: diagnostic tool for minimal hepatic encephalopathy. J Hepatol 2007;47:67-73.

16. Polman CH, Reingold SC, Banwell B, et al. Diagnostic criteria for multiple sclerosis: 2010 revisions to the McDonald criteria. Ann Neurol 2011;69:292-302.

17. Kurtzke JF. Rating neurologic impairment in multiple sclerosis an expanded disability status scale (EDSS). Neurology 1983;33:1444.

18. von Elm E, Altman DG, Egger M, et al. Strengthening the reporting of observational studies in epidemiology (STROBE) statement: guidelines for reporting observational studies. BMJ 2007;335:806-808.

19. Romero-Gómez M, Córdoba J, Jover R, et al. Value of the critical flicker frequency in patients with minimal hepatic encephalopathy. Hepatology 2007;45:879-885.

20. Bock M, Brandt AU, Kuchenbecker J, et al. Impairment of contrast visual acuity as a functional correlate of retinal nerve fibre layer thinning and total macular volume reduction in multiple sclerosis. Br J Ophthalmol 2012;96:62-67.

21. Baier ML, Cutter GR, Rudick RA, et al. Low-contrast letter acuity testing captures visual dysfunction in patients with multiple sclerosis. Neurology 2005;64:992-995.

22. Zimmermann P, Fimm B. Test for Attentional Performance (TAP)-Version 1.02. Manual. Würselen: Psytest; 1994.

23. Cutter GR, Baier ML, Rudick RA, et al. Development of a multiple sclerosis functional composite as a clinical trial outcome measure. Brain J Neurol 1999;122:871-882.

24. Cruz-Herranz A, Balk LJ, Oberwahrenbrock T, et al. The APOSTEL recommendations for reporting quantitative optical coherence tomography studies. Neurology 2016;86: 2303-2309.

25. Lang A, Carass A, Hauser M, et al. Retinal layer segmentation of macular OCT images using boundary classification. Biomed Opt Express 2013;4:1133-1152.

26. Tewarie P, Balk L, Costello F, et al. The OSCAR-IB consensus criteria for retinal OCT quality assessment. PLoS One 2012;7:e34823.

27. Schippling S, Balk LJ, Costello F, et al. Quality control for retinal OCT in multiple sclerosis: validation of the OSCAR-IB criteria. Mult Scler 2015;21:163-170.

28. Wolak ME, Fairbairn DJ, Paulsen YR. Guidelines for estimating repeatability. Methods Ecol Evol 2012;3:129-137.

29. Vaz S, Falkmer T, Passmore AE, et al. The case for using the repeatability coefficient when calculating test-retest reliability. PLoS One 2013;8:e73990.

30. Holm SA. Simple sequentially rejective multiple test procedure. Scand J Stat 1979;6: 65-70. 
31. Ross AT, ReitanIntellectual RM, Functions affective: in multiple sclerosis: a quantitative study. AMA Arch Neurol Psychiatry 1955;73:663-677.

32. Seitz AR, Sr JEN, Holloway SR, Watanabe T. Perceptual learning of motion leads to faster flicker perception. PLoS One 2006;1:e28.

33. Derrington AM, Lennie P. Spatial and temporal contrast sensitivities of neurones in lateral geniculate nucleus of macaque. J Physiol 1984;357:219-240.

34. Jacobson DM, Olson KA. Impaired critical flicker frequency in recovered optic neuritis. Ann Neurol 1991;30:213-215.

35. Raz N, Shear-Yashuv G, Backner Y, et al. Temporal aspects of visual perception in demyelinative diseases. J Neurol Sci 2015;357:235-239.

36. Petzold A, de Boer JF, Schippling S, et al. Optical coherence tomography in multiple sclerosis: a systematic review and meta-analysis. Lancet Neurol 2010;9:921-932.
37. Trip SA, Schlottmann PG, Jones SJ, et al. Retinal nerve fiber layer axonal loss and visual dysfunction in optic neuritis. Ann Neurol 2005;58:383-391.

38. Sturm W, Willmes K. On the functional neuroanatomy of intrinsic and phasic alertness. NeuroImage 2001;14(1 pt 2):S76-S84.

39. Weinges-Evers N, Brandt AU, Bock M, et al. Correlation of self-assessed fatigue and alertness in multiple sclerosis. Mult Scler J 2010;16:1134-1140.

40. Sandry M. Critical flicker frequency in multiple sclerosis. Percept Mot Skills 1963;16: 103-108.

41. Misiak H. Age and sex differences in critical flicker frequency. J Exp Psychol 1947;37: 318-332.

42. Ginsburg N, Jurenovskis M, Jamieson J. Sex differences in critical flicker frequency. Percept Mot Skills 1982;54(3 suppl):1079-1082. 


\section{Neurology \\ Neuroimmunology \& Neuroinflammation}

Temporal visual resolution and disease severity in MS

Noah Ayadi, Jan Dörr, Seyedamirhosein Motamedi, et al.

Neurol Neuroimmunol Neuroinflamm 2018;5;

DOI 10.1212/NXI.0000000000000492

This information is current as of August 14, 2018

\section{Updated Information \& Services}

References

Subspecialty Collections

Permissions \& Licensing

Reprints including high resolution figures, can be found at: http://nn.neurology.org/content/5/5/e492.full.html

This article cites 40 articles, 4 of which you can access for free at: http://nn.neurology.org/content/5/5/e492.full.html\#\#ref-list-1

This article, along with others on similar topics, appears in the following collection(s):

Attention

http://nn.neurology.org//cgi/collection/attention

Multiple sclerosis

http://nn.neurology.org//cgi/collection/multiple_sclerosis

Retina

http://nn.neurology.org//cgi/collection/retina

Visual loss

http://nn.neurology.org//cgi/collection/visual_loss

Visual processing

http://nn.neurology.org//cgi/collection/visual_processing

Information about reproducing this article in parts (figures,tables) or in its entirety can be found online at:

http://nn.neurology.org/misc/about.xhtml\#permissions

Information about ordering reprints can be found online: http://nn.neurology.org/misc/addir.xhtml\#reprintsus

Neurol Neuroimmunol Neuroinflamm is an official journal of the American Academy of Neurology.

Published since April 2014, it is an open-access, online-only, continuous publication journal. Copyright Copyright (C) 2018 The Author(s). Published by Wolters Kluwer Health, Inc. on behalf of the American Academy of Neurology.. All rights reserved. Online ISSN: 2332-7812.

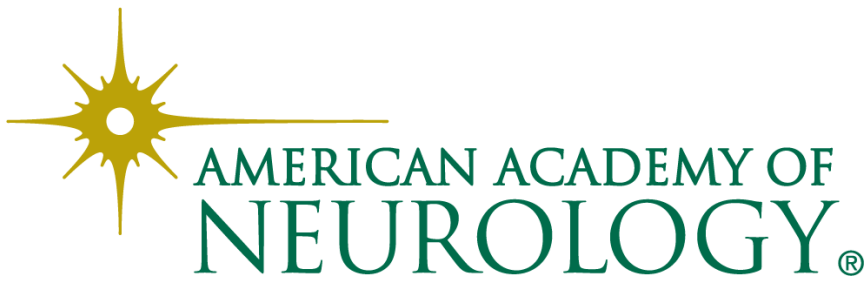

